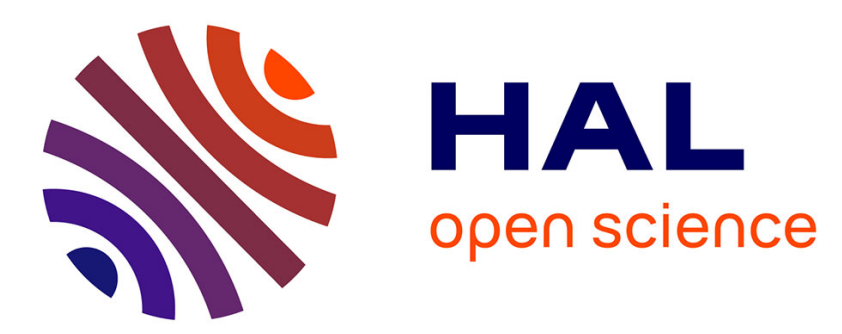

\title{
Approximation and synthesis of non integer order systems
}

\author{
Abdelbaki Djouambi, Abdelfatah Charef, Alina Voda
}

\section{To cite this version:}

Abdelbaki Djouambi, Abdelfatah Charef, Alina Voda. Approximation and synthesis of non integer order systems. 2nd IFAC Workshop on Fractional Differentiation and its Applications, FDA06, 2006, Porto, Portugal. hal-00126275

\section{HAL Id: hal-00126275 https://hal.science/hal-00126275}

Submitted on 24 Jan 2007

HAL is a multi-disciplinary open access archive for the deposit and dissemination of scientific research documents, whether they are published or not. The documents may come from teaching and research institutions in France or abroad, or from public or private research centers.
L'archive ouverte pluridisciplinaire HAL, est destinée au dépôt et à la diffusion de documents scientifiques de niveau recherche, publiés ou non, émanant des établissements d'enseignement et de recherche français ou étrangers, des laboratoires publics ou privés. 


\title{
APPROXIMATION AND SYNTHESIS OF NON INTEGER ORDER SYSTEMS
}

\author{
Abdelbaki Djouambi ${ }^{1}$, Abdelfatah Charef $^{2}$ and Alina Voda Besançon ${ }^{1}$ \\ ${ }^{1}$ LAG-ENSIEG BP 46 Rue de la Houille Blanche St Martin d'Hères \\ 38406 France \\ E-mail:djouambi_abdelbaki@yahoo.fr \\ ${ }^{2}$ Université Mantouri, Département d'Electronique \\ Route de Ain El bey, Constantine, Algérie \\ E-mail: afcharef@yahoo.com
}

\begin{abstract}
This paper presents a new method to approximate and to synthesize fractional systems represented by an explicit transfer function. We first present the distribution of relaxation times function method to approximate this type of function and hopefully to make circuit designers more aware of these advantages when designing fractal system circuits and fractal filters. Computer simulations of the circuit model by $\mathrm{B}^{2}$ SPICE were used to demonstrate clearly our derivation results. An analog circuit model of the foster network can be synthesized.
\end{abstract}

Keywords: Fractional systems, Approximation, Identification and Distribution of Relaxation Times.

\section{INTRODUCTION}

Fractional order systems or fractal systems are defined in terms of the shape of their spectra which is proportional to reciprocal frequency and which is generally called $1 / \mathrm{f}^{\beta}$ spectra (Mandelbrot, et al., 1967) and (Mandelbrot, et al., 1983). Such spectra have been observed in a tremendous variety of dissimilar natural phenomena.

Numerous studies have been made about this phenomenon ever since it was pointed out by (Van Der Ziel, 1950). Many empirical and mathematical models have also been introduced to describe these processes with $1 / \mathrm{f}^{\beta}$ type spectra. During the past decade, we have seen tremendous growth of study in this subject especially toward the applications in meteorology, astronomy, geology, physiology and many other fields. Recently, fractal analytical techniques and methodologies have been used by scientists in different fields in order to explain the ubiquitous $1 / \mathrm{f}^{\beta}$ processes which have been characterizing a wide range of natural phenomena, see (Dutta P., et al., 1981) and (Sun H. et al., 1984). These scientists have found that these processes are mediated by the fractal nature of the phenomena themselves. Hence, these observations suggest a link between fractals and system theory.
The equation that is commonly used to describe some phenomenon has been expressed by an inverse power law equation as:

$$
F(s)=\frac{K}{s^{m}}
$$

Where, $k$ is a positive constant, $\mathrm{s}=\mathrm{jw}$, and $m$ is a positive real number.

Hence many of the complex fractal systems which have been represented as the inverse power law equation can best be represented by the ColeCole function and described in the Laplace transform domain by the explicit transfer function (Cole K. S., et al., 1941):

$$
F_{\exp }(s)=\frac{k}{s^{m}+a}
$$

Where, $k$ and $a$ is a positive constant, $s=j w$, and $m$ is a positive real number. This type of expression gives a much suitable mathematical representation to the natural phenomena so that its low frequency magnitude is finite instead of infinite. This is usually the case for the magnitude of natural phenomena at very low frequency.

The analysis of the response to elementary input of these fractional order systems shows that they posses a remarkable performance as compared to the 
integer order systems, see (Oustaloup A., et al. 2000) (Oustaloup A., et al. 1997), (Charef A., et al., 1992), (Sun H., et al., 1990) and (Charef A., et al., 2001).

In this paper we present a new method to approximate the transfer function given by equation (2) using the distribution of relaxation times function.

The materials collected in this paper are grouped into two main parts:

Part I summarizes the approximation by a rational function of equation (2) which we found to be the basic element for representation of fractional order systems.

Part II deals with the synthesis with the Foster's network of the approximated fractional system.

\section{APPROXIMATION}

Many of real physical systems can be batter represented by an explicit fractional transfer function given by the following transfer function (Cole K. S., et al., 1941):

$$
F(s)=\frac{1}{1+\left(\tau_{0} s\right)^{m}}
$$

where $m \in \mathfrak{R}$.

Because of their mathematical representation in the frequency domain are irrational function, direct analysis methods and corresponding time domain behavior seems difficult to handle. For the purpose of identification, analysis, synthesis and simulation of such systems, the need arises for a rational function approximation. Two cases were presented here:

Case 1: $0<m<1$

To extend Debye model (Debye, et al., 1929) which has only one relaxation time, the distribution of relaxation times has also been derived. This concept was introduced by Fuross and Kirkwood (Fuross, R., et al., 1941) derived a formula to obtain the distribution of relaxation times function $G(\tau)$ directly from the original transfer function as fellow:

$$
F(s)=\int_{0}^{\infty} \frac{G(\tau)}{1+\tau s} d \tau
$$

K. S. Cole and R. H. Cole applied this method to find the distribution function $G(\tau)$ for the model given in equation (3):

$$
G(\tau)=\frac{1}{2 \pi} \frac{\sin [(1-m) \pi]}{\cosh \left[m \log \left(\frac{\tau}{\tau_{0}}\right)\right]-\cos [(1-m) \pi]},
$$

By sampling the distribution function $G(\tau)$ given in equation (4) for a limited bandwidth at logarithmically equidistant points $\tau_{i}$, for $i=1, \ldots, 2 N-1$

we can write:

$$
G(\tau)=\sum_{i=1}^{2 N-1} G\left(\tau_{i}\right) \delta\left(\tau-\tau_{i}\right)
$$

where, $\tau_{i}=\tau_{0}(\lambda)^{(N-i)}$, for $i=1,2, \ldots, 2 N-1$,

and $\lambda>1$ is the ratio of time constant to the next one or the ratio of a pole to the previous one, where the poles are:

$$
s_{i}=1 / \tau_{i}, \text { for } i=1,2, \ldots, 2 N-1
$$

Then, the transfer function of equation (3) can be approximated by:

$$
F(s) \approx F_{N}(s)=\sum_{i=1}^{2 N-1} \frac{G\left(\tau_{i}\right)}{1+\tau_{i} s}
$$

Using MATLAB Optimization Toolbox, The values of the ratio $\lambda$ are calculated according to the following criterion:

$$
\lambda=\arg \min \left(\max _{w \in\left[w_{\min }, w_{\max }\right.}\left\{|| F_{N}(j w)|-| F(j w)||\right\}\right)
$$

in the frequency band of interest $w \in\left[10^{-6}, 10^{6}\right\rfloor \mathrm{rd} / \mathrm{s}$ for different values of $N$ and $m$. The values of this ratio for four different values of $m$ and four different values of $N$ are given in table (Tab.1).

Tab.1: The optimal values of the ratio $\lambda$, the maximum magnitude error $\left(\max _{e g}\right)$ and the maximum phase error $\max _{e p h}$ for different values of $m$ and $N$, with $\tau_{0}=1$.

\begin{tabular}{|c|c|l|l|l|l|}
\hline \multicolumn{2}{|c|}{$\mathrm{m}$} & \multicolumn{1}{|c|}{$\mathrm{N}$} & 20 & 30 & 40 \\
\hline \multirow{4}{*}{0.2} & $\lambda$ & 10.434 & 3.040 & 2.650 & 2.711 \\
\cline { 2 - 6 } & $\max _{e g}$ & 8.851 & 2.776 & 0.200 & 0.026 \\
\cline { 2 - 6 } & $\max _{e p h}$ & 3.880 & 4.197 & 0.890 & 0.100 \\
\hline \multirow{4}{*}{0.4} & $\lambda$ & 7.126 & 2.716 & 2.718 & 2.719 \\
\cline { 2 - 6 } & $\max _{e g}$ & 6.520 & 0.395 & 0.010 & 0.003 \\
\cline { 2 - 6 } & $\max _{e p h}$ & 4.260 & 4.031 & 0.040 & 0.006 \\
\hline \multirow{4}{*}{0.7} & $\lambda$ & 4.727 & 2.717 & 2.721 & 2.721 \\
\cline { 2 - 6 } & $\max _{e g}$ & 4.630 & 0.023 & 0.010 & 0.010 \\
\cline { 2 - 6 } & $\max _{e p h}$ & 9.170 & 0.340 & 0.080 & 0.090 \\
\hline \multirow{3}{*}{0.9} & $\lambda$ & 4.250 & 3.844 & 3.844 & 3.844 \\
\cline { 2 - 6 } & $\max _{e g}$ & 2.370 & 1.550 & 1.550 & 1.550 \\
\cline { 2 - 6 } & $\max _{e p h}$ & 5.650 & 4.200 & 4.190 & 4.190 \\
\hline
\end{tabular}

As an illustration example, we have chosen a fractional order system which is represented by the following function:

$$
F(s)=\frac{1}{1+s^{0.4}}
$$

The figures (1) and (2) show the Bode plots of the original function and that of its rational approximation function with $N=30$ and $\lambda=2.718$. The figures show that the two curves are overlapping. 


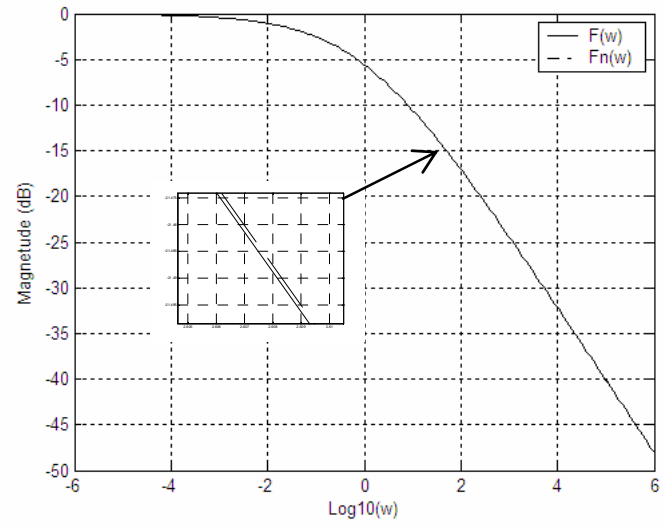

Fig.1. Magnitude plot of $F(s) a n d F_{N}(s)$

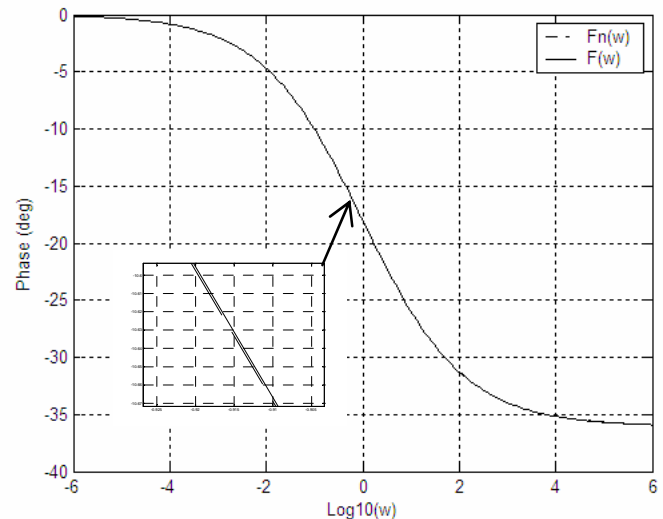

Fig.2. Phase plot of $F(s) a n d F_{N}(s)$

Using direct method time domain simulation, see (Oustaloup A., 1995), the step response of the original system and that of the approximated one were presented in figure (3), the figure shows that the two curves are superimposed.

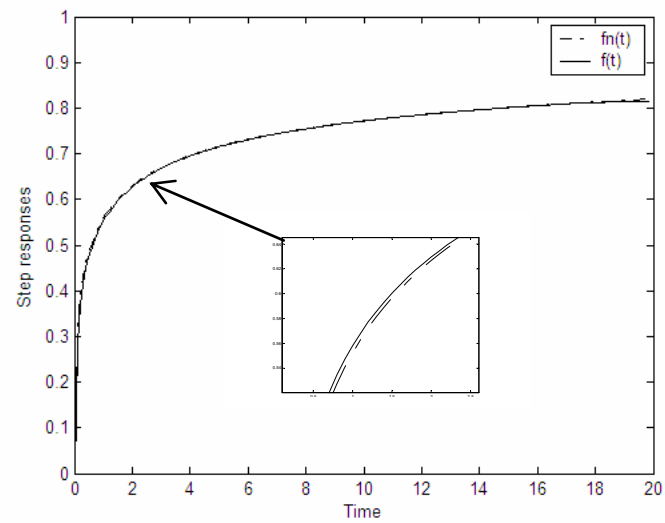

Fig.3 Step response of the considered system and its approximation

Case 2: $\quad 1<m<2$

Based in frequency behavior of the considered system at low frequency, at $w=1 / \tau_{0}$ and at high frequency the approximation of $F(s)$ can be expressed as follows:

$$
F(s) \approx F_{a}(s)=\frac{\left(\tau_{0} s\right)^{(2-m)}+1}{\left(\tau_{0} s\right)^{2}+e \tau_{0} s+1}
$$

where $e$ is given by the following equation

$$
e=2 \sqrt{\left(1-\cos ^{2}(m \pi / 2)\right)}
$$

It can be easily shown that:

for $w<<1 / \tau_{0}, w=1 / \tau_{0}$ and $w>>1 / \tau_{0}$

$$
|F(j w)|=\left|F_{a}(j w)\right|
$$

Tab. 2 shows the optimal values of $e$ which minimize the maximum gain error given as follow:

$$
e_{o p}=\arg \min \left(\max _{w \in\left[w_{\min }, w_{\text {max }}\right]}\left\{|| F_{a}(j w)|-| F(j w) \|\right\}\right)
$$

in the frequency band of interest $w \in\left[10^{-6}, 10^{6}\right\rfloor \mathrm{rd} / \mathrm{s}$ for different values of $m$ and $\tau_{0}=1$.

Tab.2. The optimal values of $e$ in terms of $m, \tau_{0}=1$

\begin{tabular}{|c|c|c|}
\hline$m$ & $e_{o p}$ & $\max _{e g_{(d B)}}$ \\
\hline 1.1 & 1.98 & 0.1 \\
\hline 1.2 & 1.89 & 0.4 \\
\hline 1.3 & 1.83 & 0.8 \\
\hline 1.4 & 1.79 & 1.3 \\
\hline 1.5 & 1.75 & 1.9 \\
\hline 1.6 & 1.49 & 2.7 \\
\hline 1.7 & 1.29 & 3.5 \\
\hline 1.8 & 0.92 & 4.4 \\
\hline 1.9 & 0.45 & 5.3 \\
\hline
\end{tabular}

The function $F_{a}(s)$ can be represented by the following equation:

Where

$$
F_{a}(s)=F_{1}(s) F_{2}(s)
$$

$$
F_{1}(s)=\frac{1}{\left(\tau_{0} s\right)^{2}+e \tau_{0} s+1}
$$

is a second order ordinary function, and the function:

$$
F_{2}(s)=\left(\tau_{0} s\right)^{(2-m)}+1
$$

is a fractional transfer, which has the same form of the inverse of the function in equation (3), where, $1<m<2$.

As an illustrative example, we choose a fractional order system which is represented by the following function:

$$
F(s)=\frac{1}{1+s^{1.4}}
$$

Figure (4) and figure (5) show the Bode plot of the original function and that of its approximation with $e=1.79$ and $N=30$; the figures show that the two curves are overlapping with a small difference in phase responses due to the approximation error. 


\section{CONCLUSION}

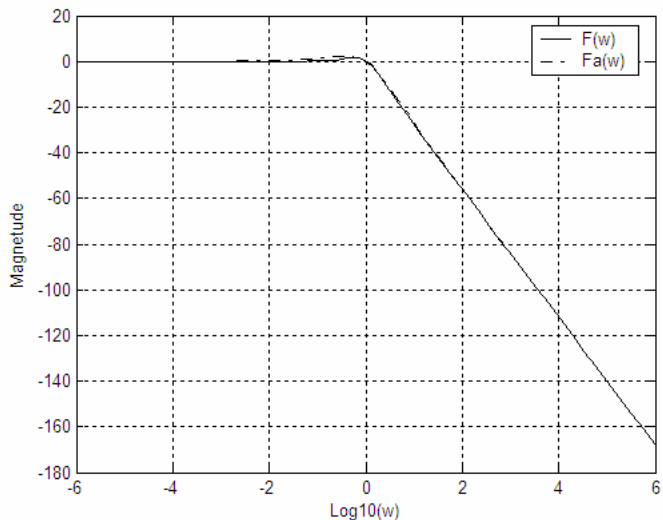

Fig.4. Magnitude plot of $F(s) a n d F_{a}(s)$

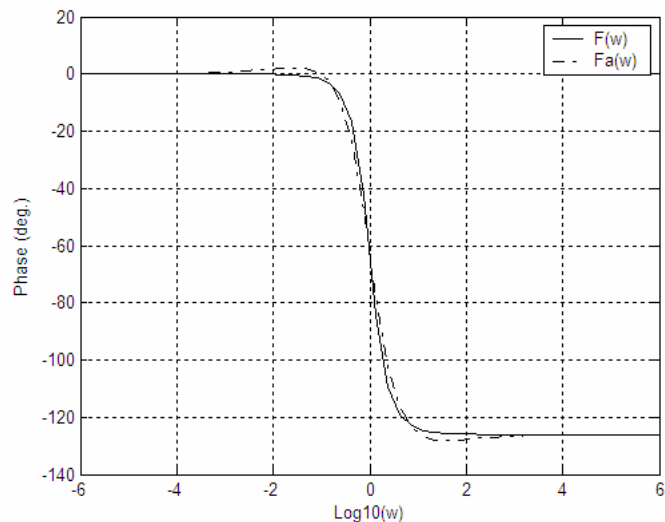

Fig. 5 Phase plot of $F(s) a n d F_{a}(s)$

\section{SYNTHESIS}

Each element of the equation (7) can be easily replaced by a respective driving point impedance of the following RC circuit type:

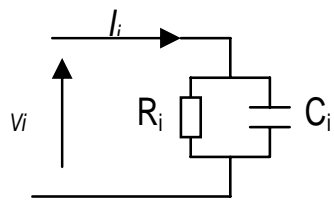

$$
\frac{V_{i}}{I_{i}}=Z_{i}(s)=\frac{R_{i}}{1+s R_{i} C_{i}}
$$

Fig. 6 Elementary RC circuit

Where, $R_{i}=G\left(\tau_{i}\right)$ and $C_{i}=\tau_{i} / G\left(\tau_{i}\right)$

for $i=1,2, \ldots, 2 N-1$.

Thus, the Cole-Cole function of equation (2) can be synthesized by cascaded RC cells as:

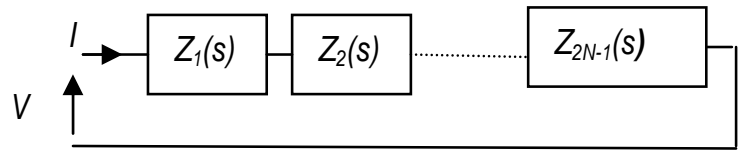

Fig. 7 Cascade RC cells

$$
\frac{V}{I}=\frac{1}{1+\left(s \tau_{0}\right)^{m}}
$$

The results obtained in this paper validate the link between non integer derivation and the distributed parameter systems. To approximate the Cole-Cole function by a first-order time-varying differential equation whose solution is also the inverse LaplaceTransform of the original fractional system, the distribution of relaxation times was used. By doing this transformation, the singularity function method for the explicit fractional system was used. The circuit representation consisted in a cascade of $\mathrm{RC}$ circuits of the singularity function.

\section{REFERENCES}

Oustaloup A., La dérivation non entière, théorie, synthèse et application, HERMES Ed., Paris, 1995.

Oustaloup A., Moreau X. and Nouillant M., From fractal robustness to non integer approach in vibration insulation: the CRONE suspension Proceeding of $36^{\text {th }}$ Conference on Decision and control, California, USA, 1997, pp. 4979-4984.

Oustaloup A., levron F., and Mathieu B., Frequencyband complex non integer differentiator: Characterization and synthesis IEEE Trans. Circuit Syst. I., vol. 47, 2000,

Cole, K. S. and R. H. Cole, Dispersion and Absorption in Dielectrics, Alternating Current Characterization, J. Chem. Physics, 9, pp 341351, 1941.

Charef A., Sun H., Tsao Y., and Onaral B., Fractal systems as represented by singularity function, IEEE Trans. Aitom. Cont., vol. 37 N $^{\circ}$ 9, 1992.

Charef A. And Djouambi A., Fractional Order Feedback Control Systems, JIEEEC2001 $4^{\text {th }}$ conference, Jordan, 2001.

Dutta P, and Horn P.M., Low frequency fluctuations in solids: 1/f noise, Review of modern physics, vol. 53, N³, July 1981.

Debye, P., Polar Molecules, Dover Publication, NY, 1929.

Fuross, R. M., J.K. Kirkwood, Electrical Properties of Solids VIII-Dipole Moments in polyvinyl Chloride Biphenyl Systems, J. Am. Chem. Soc., 63, pp 385-394, 1941.

Mandelbrot, B, B. The Fractal Geometry of Nature, W. H. Freeman \& Co., 1983.

Mandelbrot B.B, Some noises with 1 ! f spectrum, a bridge between direct current and white noise, IEEE Trans. Infor. Theory, vol. IT-13, N², April 1967.

Sun H, and Onaral B., A unified approach to represent metal electrode interface, IEEE Trans. Biomed. Eng., vol. BME-31, July 1984

Sun H. And Charef A., Fractal system - a time domain approach, Anal of Biom. Eng., Vol. 18, 1990.

Van Der Zeil, A., On the noise Spectra of Semiconductor Noise and of Flicker Effect, Physical, 16, pp 359-372, 1950. 